\title{
PAMUK METÍL ESTERİNE N-HEPTAN KATKISININ MOTOR PERFORMANSI VE YANMA KARAKTERISTIKKLERINNE ETKİLERİNİN İNCELENMESİ
}

\author{
Mehmet ÇELIK ${ }^{1}$, Hamit SOLMAZ ${ }^{2}$, H. Serdar YÜCESU ${ }^{2}$ \\ ${ }^{1}$ Niğde Üniversitesi, Niğde Teknik Bilimler Meslek Yüksekokulu, 51200, Niğde, Türkiye \\ ${ }^{2}$ Gazi Üniversitesi, Teknoloji Fakültesi, Otomotiv Mühendisliği Bölümü, 06500, Ankara, Türkiye \\ mehmetcelik@nigde.edu.tr, hsolmaz@gazi.edu.tr, yucesu@gazi.edu.tr
}

(Geliş/Received: 01.07.2014; Kabul/Accepted: 23.07.2015)

ÖZET

\begin{abstract}
Yakıt katkılarının dizel motor performansına etkileri birçok araştırmacı tarafından çalışıııış ve umut verici sonuçlar elde edilmiştir. Katkı maddeleri yanma esnasında katalizör etkisi göstererek yakıt kararsızlı̆̆ı reaksiyonlarını hızlandırmakta ve motor performansı üzerinde olumlu etkiler oluşturmaktadır. Bu çalışmada; rafine edilmiş pamuk yağından transesterifikasyon yöntemi ile biyodizel üretilmiş, üretilen biyodizellere belirli oranlarda n-heptan katılmış ve test edilmiş̧ir. Deneyler tek silindirli bir dizel motorunda sabit devirde ve tam yükte yapılmıştır. Pamuk metil esteri ( $\mathrm{PH} 0)$ yakıtı içerisine n-heptan ilavesi yakıt atomizasyonunu iyileștirmiş ve yanma verimliliği artmıştır. Maksimum güç artış1 \%8 n-heptan içeren pamuk metil esteri ile (PH8) \%7.52 olmuştur. Tüm yakıtlar için maksimum silindir gaz basınçları ve maksimum 1sı yayılımı hemen hemen aynı krank açısında oluşmuştur. Çalışmada \% $8 \mathrm{n}$-heptan karışımı motor performans ve yanma özellikleri bakımından en iyi sonucu vermiştir.
\end{abstract}

Anahtar Kelimeler: Pamuk metil esteri, yakıt katkı maddesi, yanma karakteristikleri, motor performansı

\section{EXAMINATION OF THE EFFECTS OF N-HEPTAN ADDITION TO COTTON METHYL ESTER ON THE ENGINE PERFORMANCE AND COMBUSTION CHARECTERISTICS}

\begin{abstract}
The fuel additives have been studied by many researchers on diesel engine performance and encouraging results have been obtained. During the combustion fuel additives provide the catalyst effect, accelerates the reaction instability and create positive effects on engine performance. In this study; biodiesel was produced by transesterification from the refined cottonseed oil, a certain amount of $n$-heptane were added in biodiesel and combustion and performance tests were conducted. The experiments was made in a single-cylinder diesel engine at a constant speed and full load. n-heptane added into the cotton methyl ester (PH0) fuel improved the fuel atomization therefore combustion efficiency increased. The maximum power increase was $7.52 \%$ in cotton methyl ester fuel containing $8 \% \mathrm{n}$-heptan (PH8). The maximum gas pressure and maximum heat release are formed in almost the same crank angle for all fuels. The $8 \% \mathrm{n}$-heptane mixture given the best results in terms of engine performance and combustion characteristics.
\end{abstract}

Keywords: Cottonseed methyl ester, fuel additive, combustion characteristics, engine performance

\section{GIRISS (INTRODUCTION)}

Dünyada her geçen gün artış göstermekte olan nüfus, sanayileşme ve teknolojik gelişmeler enerji tüketiminde artışlara yol açmakta ve çevre kirliliğine de önemli derecede olumsuz etkisi olmaktadır [1].
Azalan petrol rezervleri ve artan çevre bilinci ile birlikte yenilenebilir enerji kaynakları daha fazla ilgi çekmektedir [2]. Bitkisel yağlardan, hayvansal yağlardan ve atık yağlardan üretilen biyodizel dizel motorlarda en çok kullanılan yenilenebilir enerji kaynaklarından birisidir $[3,4]$. 
27 Eylül 2011 tarihli Resmi Gazete'de yayınlanan tebliğe göre; dizel yakıtı içerisine 1 Ocak 2014 tarihinden itibaren \%1, 1 Ocak 2015 tarihinden itibaren $\% 2$ ve 1 Ocak 2016 tarihinden itibaren $\% 3$ yerli tarım ürünlerinden üretilmiş biyodizelin kullanımı zorunlu hale getirilmiştir [5]. Dizel ile kıyaslandığında biyodizelin çok fazla avantajı bulunmaktadır. Aromatik içermez, sülfür yoktur ve \%10-12 ağırlığında oksijen içerir [2]. Dizel motorlarında kullanılan yakıtın fiziksel ve kimyasal özellikleri motor performansı, yakıt ekonomisi ve emisyon karakteristiklerini etkilemektedir [6]. Motor performansı; enjekte edilen yakıtın kalitesi, yanma odasındaki hava/yakıt karışımı, yakıtın atomizasyonu, buharlaşması, yakıtın yoğunluğu ve viskozitesi ile alakalıdır [7]. Yakıtın yoğunluğu motor performansını direkt etkileyen bir özelliktir. Setan sayısı ve alt 1sıl değer gibi birçok özellik yakıtın yoğunluğu ile ilgilidir. Yakıtın yoğunluğu ve viskozitesi yakıt püskürtme özelliklerini etkilediğinden; motor performansı, yanma ve emisyon karakteristikleri üzerinde etkiye sahiptir [2].

Motor performansı ve egzoz emisyonlarını azaltmak için birçok araştırma yakıt katkılarına odaklanmıştır. Yakıt özellikleri ve yanmayı iyileştirmek için yakıt katkılar1 kullanılabilmektedir [8]. Yakıt katk1s1 kullanımının dizel motor performansına ve yanma karakteristiklerine etkilerini incelemek amaciyla birçok çalışma gerçekleştirilmiştir [9]. Katkı maddeleri yanma esnasında katalizör etkisi göstererek yakıt kararsızlığı reaksiyonlarını hızlandırır [1]. Biyodizel yüksek viskozite ve yoğunluğa sahiptir. Setan sayısının artışı tutuşma gecikmesi süresinin kısalmasına etkili olduğundan düșük yüklerde motora ilk hareket vermeyi kolaylaştırdığı ve motor performansının iyileştiği ifade edilmektedir [10]. Bir motorda yanma karakteristikleri; motor performansı ve emisyonlarını yorumlama açısından çok önemlidir. Yanma karakteristikleri; maksimum silindir gaz basıncı ve krank açısı cinsinden yeri, 1sı yayılımı, kümülatif 1sı yayılımı, yanma ve püskürtme zamanlarına bağlı olarak elde edilen tutuşma gecikmesi, toplam yanma süresi ve ani yanma süresi olarak incelenmektedir [11-12].

$\mathrm{Bu}$ çalışmada biyodizel üretimi için; bitkisel üretim maliyetlerinin çok olması, tohumundan üretilen yağın alternatif kullanım alanları olmaması sebebiyle ülkemizde ekim alanı azalan pamuk bitkisinin tohumundan elde edilen pamuk yağı tercih edilmiştir. Biyodizelin motor performansını etkileyen yakıt özelliklerini iyileştirmek amacıyla içerisine n-heptan katılarak alternatif motor yakıtı olarak değerlendirilebilmesi düşünülmüştür.

\section{MALZEME VE YÖNTEM (MATERIAL AND METHODS)}

Deneylerde kullanılan biyodizel rafine edilmiş pamuk yağından transesterifikasyon yöntemi ile üretilmiştir. Katalizör olarak $\mathrm{NaOH}$ (3.5 g/L) ve Metanol (hacimce \%20) kullanılmıştır. Transesterifikasyon akış şeması Şekil 1'de gösterilmiştir.

Reaksiyon $60 \pm 1{ }^{\circ} \mathrm{C}$ sabit sicaklık altında 1 saat boyunca gerçekleştirilmiştir. Biyodizel ve gliserin ayrışmasından sonra yıkama yapılmıştır. Biyodizel üretimi için daha önce yapılan çalışmalardaki maksimum biyodizel veriminin elde edildiği üretim parametreleri seçilmiştir [35, 36, 37, 38]. Elde edilen pamuk metil esteri içerisine hacimce $\% 4, \% 8, \% 12$, $\% 16$ ve \%20 oranlarında n-heptan katılmıștır. Pamuk metil esteri ve n-heptan karışımları adlandırması ve bunlara ilişkin kısaltmalar içerisinde n-heptan yüzdesine göre yapılmıştır. Buna göre katkısız pamuk metil esteri (PH0), hacimce \%4 n-heptan katıldığında (PH4), hacimce \%8 n-heptan katıldı̆̆ında (PH8), hacimce \%12 n-heptan katıldığında (PH12), hacimce $\% 16$ n-heptan katıldığında (PH16) ve hacimce \%20 nheptan katıldığında (PH20) kısaltmaları kullanılmış, bu yakıtların bazı özellikleri Tablo 1'de görülmektedir. Tablo 1 incelendiğinde hacimce $\% 8 \mathrm{n}$ heptan oranından sonraki artışlarda yakıt özellikleri yakıtın kullanılabilirliğini olumsuz etkilemektedir. nheptan oranı arttıkça parlama noktası değerleri çok düşmektedir. n-heptane $\mathrm{H}_{3} \mathrm{C}\left(\mathrm{CH}_{2}\right)_{5} \mathrm{CH}_{3}$ veya $\mathrm{C}_{7} \mathrm{H}_{16}$ formülüne sahip düz zincirli alkandır. n-heptane kimyasal özellikleri Tablo 2'de görülmektedir.

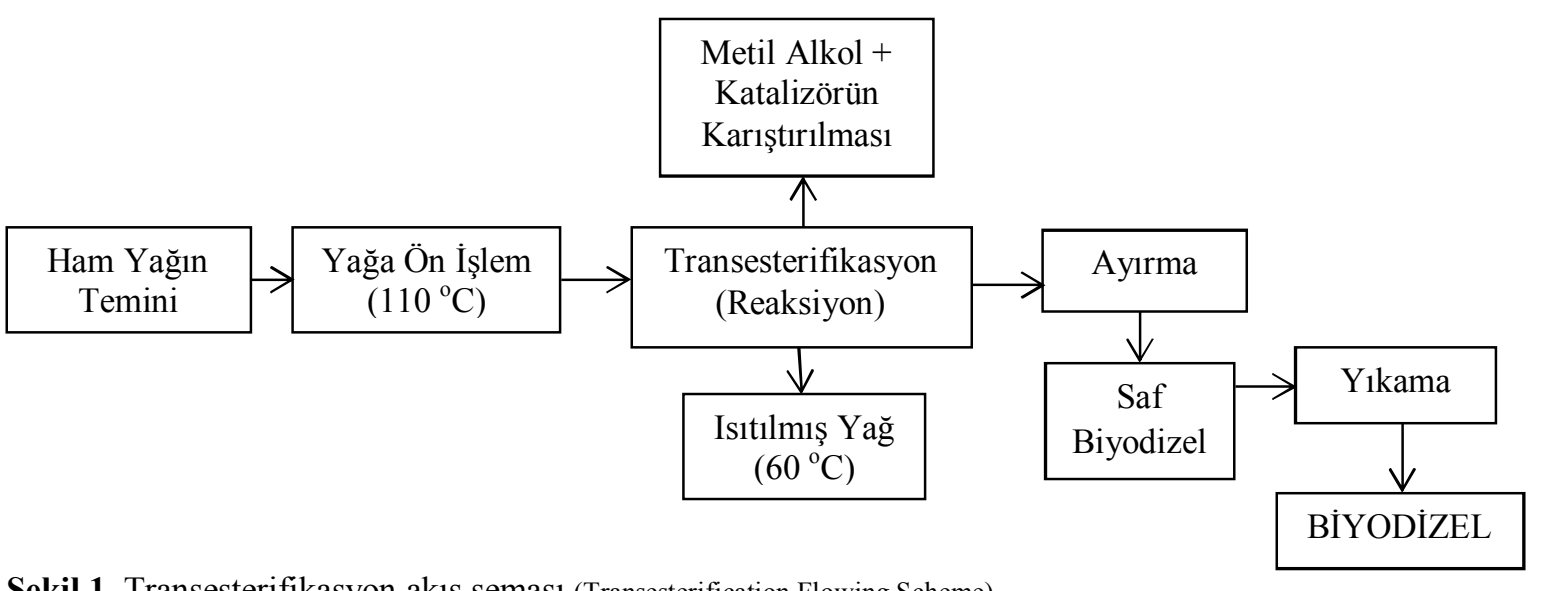

Şekil 1. Transesterifikasyon akış şeması (Transesterification Flowing Scheme) 
n-heptane setan sayısı yanma verimliliğini arttıran karışım özelliklerinden dolayı yüksektir [13]. nheptane dizele alternatif yakıt olarak da kullanılmaktadır. Dizele benzer yanma özellikleri gösteren bileşen türlerinden oluşur. Tutuşma özelliği, buharlaşma, yanma verimliliği ve kirletici emisyon oluşumu gibi birçok özellik yönünden dizele uyum sağlar [14]. Yüksek ucuculuk özelliği püskürtme sırasındaki atomizasyon ve buharlaşmanın iyileşmesine ve sonuç olarak yanmayı başlatabilecek bölgelsel hava/yakıt karışımlarının daha kolay hazırlanabilmesini sağlar. Bu nedenle özellikle düşük sıcaklık ve düşük basınçta soğuk alev bölgesinde daha iyi yanma özellikleri sergilemektedir [15].

Tablo 1. Test yakıtlarının fiziksel ve kimyasal özellikleri (Chemical and physical properties of the test fuels)

\begin{tabular}{|c|c|c|c|}
\hline Yakıt & $\begin{array}{c}\text { Kinematik } \\
\text { Viskozite }\end{array}$ & $\begin{array}{c}\text { Parlama } \\
\text { Noktası }\end{array}$ & Yoğunluk \\
\hline $\mathbf{( \mathbf { m m } ^ { \mathbf { 2 } } / \mathbf { s } )}$ & $\left.\mathbf{(}^{\mathbf{}} \mathbf{C}\right)$ & $\begin{array}{c}\mathbf{1 5} \\
\mathbf{( g / m l} \mathbf{~ C}\end{array}$ \\
\hline PH0 & 4.60 & 175 & 0.885 \\
\hline PH4 & 3.59 & 102 & 0.876 \\
\hline PH8 & 3.01 & 53 & 0.872 \\
\hline PH12 & 2.70 & 21 & 0.865 \\
\hline PH16 & 2.38 & 17 & 0.855 \\
\hline PH20 & 2.10 & 10 & 0.850 \\
\hline
\end{tabular}

Tablo 2. n-heptane Kimyasal Özellikleri (Chemical properties of the $n$-heptane) [16]

\begin{tabular}{|l|c|c|}
\hline & Birim & Limit \\
\hline Formül & $\mathrm{CH}_{3}\left(\mathrm{CH}_{2}\right)_{5} \mathrm{CH}_{3}$ veya $\mathrm{C}_{7} \mathrm{H}_{16}$ \\
\hline Molar Ağırlık & $\mathrm{g} / \mathrm{mol}$ & 100.2 \\
\hline CAS Numarası & & $142-82-5$ \\
\hline Yoğunluk & $20^{\circ} \mathrm{C}^{\prime} \mathrm{de} \mathrm{g} / \mathrm{ml}$ & 0.68 \\
\hline Kaynama Noktası & ${ }^{\circ} \mathrm{C}$ & $97-98$ \\
\hline Kinematik Viskozite & $\mathrm{mm}^{2} / \mathrm{s}$ & 0.559 \\
\hline Parlama Noktası & ${ }^{\circ} \mathrm{C}$ & -1 \\
\hline Buhar Basınc1 & $20{ }^{\circ} \mathrm{C}^{\prime} \mathrm{de} \mathrm{kPa}$ & 4.8 \\
\hline
\end{tabular}

Çalışmada; Tablo 3'de teknik özellikleri verilen tek silindirli bir dizel motoruna motor yükleme donanımı olarak Cussons marka P8160 tipi motor deney düzeneği kullanılmıştır. İndikatör sistemi; Cussons marka P4100 model yanma analiz cihazı, AVL marka 3009 model şarj amplifikatörü, AVL marka sensörler ve National Instruments marka veri aktarım kartı ile enkoderden oluşmaktadır. Deney düzeneğinin şematik görünümü Şekil 2'de görülmektedir.
Ham silindir basıncı değerlerinde zamana bağlı olarak oluşan kayma ölçülen ham verilerde bir takım farklılıklar gerçekleşebilmekte ve oluşan bu farklılıkların ortadan kaldırarak işlenebilir hale getirilmesi gerekmektedir. Her bir çevrim için 2000 adet basınç verisi alınmaktadır. Kayma, 2000 adet noktada alınan basınç değerlerinin her birinin kaymasının üst üste gelmesi ile oluşan kümülatif değerdir. Her bir düğüm noktasının ağırlığına göre oranlama yapılarak ilk değerden çıkarılması ile her bir çevrim için kayma miktarında düzeltme yapılmaktadır. Daha sonra çevrimsel farklılıkların etkisini ortadan kaldırmak amacıyla 50 adet ardışık çevrimin düzeltmeleri yapılmış ve analizler için ortalaması alınmıştır [17]. Motor deneyleri maksimum momentin elde edildiği $2200 \mathrm{~d} / \mathrm{d}$ sabit devirde ve tam yükte yapılmıştır.

Tablo 3. Deney motorunun teknik özellikleri (Technical specification of the test engine)

\begin{tabular}{|l|l|}
\hline & Özellikler \\
\hline Motor Tipi & DI dizel motoru \\
\hline Silindir Sayısı & 1 \\
\hline Silindir çapı $(\mathrm{mm})$ & 86 \\
\hline Kursu $(\mathrm{mm})$ & 68 \\
\hline Strok hacmi $\left(\mathrm{cm}^{3}\right)$ & 395 \\
\hline Sıkıştırma oranı & $18: 1$ \\
\hline Maksimum motor devri $(\mathrm{d} / \mathrm{d})$ & 3600 \\
\hline Maksimum motor gücü & $5.4(3000 \mathrm{~d} / \mathrm{d}$ 'da $)$ \\
\hline Maksimum moment $(\mathrm{Nm})$ & $19.6(2200$ \\
\hline
\end{tabular}

İndikatör sistemi silindir basınç sensörü, yakıt hat basınç sensörü, şarj amplifikatörleri, enkoder, veri aktarım kartı ve bilgisayardan oluşmaktadır. İndikatör sisteminde; AVL marka 8QP500c model su soğutmalı quartz silindir basınç sensörü kullanılmıştır [17].

Silindir içi basınç verileri 1S1 dağılım oranını hesaplamak için kullanılmıştır. Isı dağılım oranı termodinamiğin birinci yasası uygulanarak Eş. 1 ile hesaplanmıştır.

$$
\frac{d Q}{d \theta}=\frac{k}{k-1} P \frac{d V}{d \theta}+\frac{1}{k-1} V \frac{d P}{d \theta}
$$

Isı dağılım oranı hesaplanırken silindirden silindir duvarına olan 1Sı transferi ihmal edilmiştir. Segmanlarda ve supaplarda meydana gelen gaz kaçağına bağlı olarak silindir içi kütlenin değişmediği kabul edilmiştir. Aynı zamanda silindir içerisindeki dolgunun ideal gaz olduğu ve yanma odasındaki termodinamik özelliklerin düzenli olduğu kabulleri yapılmıştır [25]. 


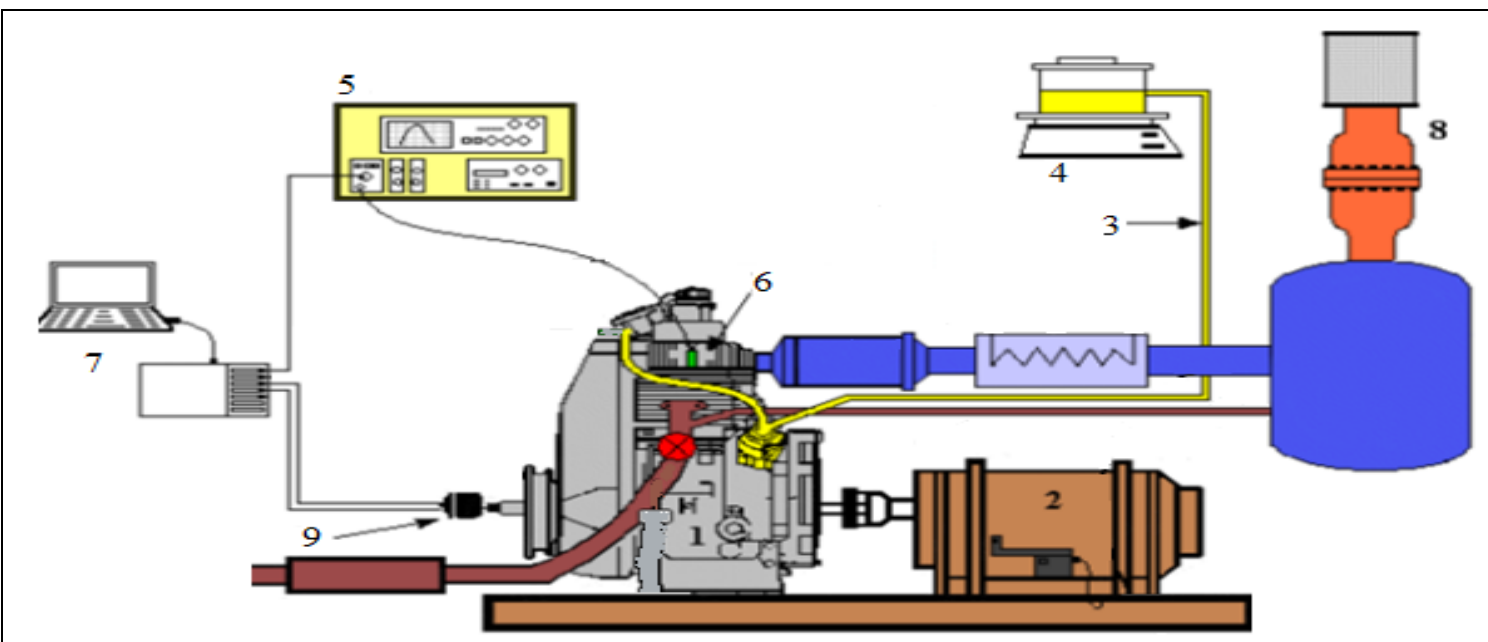

1-Deney motoru 2-DC dinamometre 3-Dizel yakıt enjeksiyon sistemi ve yakıt hatt1 4-Hassas terazi 5-Yanma analiz cihazı 6-Silindir basınç sensörü 7-Bilgisayar ve veri aktarım kartı 8- Laminer akış metre 9-Enkoder

Şekil 2. Deney düzeneğinin şematik görünümü ( Shematic view of the experimental setup)

\section{BULGULAR VE TARTIŞMA (RESULTS AND DISCUSSION)}

Şekil 3 ve Şekil 4'de pamuk metil esteri n-heptan karışımının motor devir sayısına bağlı moment ve güç değişimleri görülmektedir. Moment eğrisi incelendiğinde maksimum moment $2200 \mathrm{~d} / \mathrm{d}$ 'de PH8 yakıtı ile $19.92 \mathrm{Nm}$ olarak elde edilmiştir. PH0, PH4, PH12, PH16 ve PH 20 'da yakitlarında 2200 d/d'de maksimum moment sirasıyla 18.47 - 18.9 - 19.77 19.6 - $19.5 \mathrm{Nm}$ elde edilmiştir. Maksimum güç 2750 d/d'de PH8 yakıtınta $5.16 \mathrm{~kW}$ elde edilirken PH0 göre PH8 yakıtında \%7.52 güç artışı olmuştur. Diğer nheptan karışımlarının $2750 \mathrm{~d} / \mathrm{d}$ 'de $\mathrm{PH0}$ yakıtına göre güç değişimi ise sirasıyla PH4'de \%1.04, PH12'de \%2.63, PH16'da \%5.41 ve PH20'de \%5.27 artı̧̧ olmuştur.

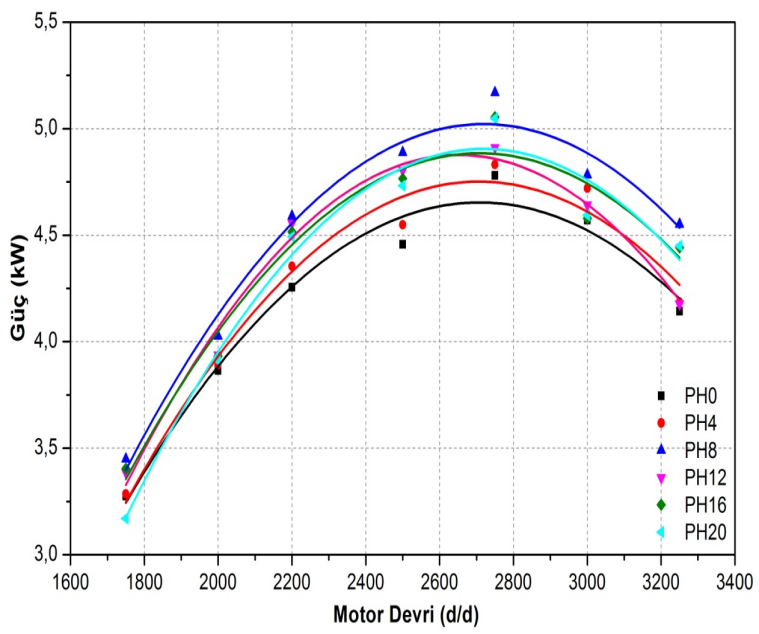

Şekil 3. Motor gücünün motorun devir sayısı ile değişimi (tam yük) (Change of engine power with engine speed-full load)

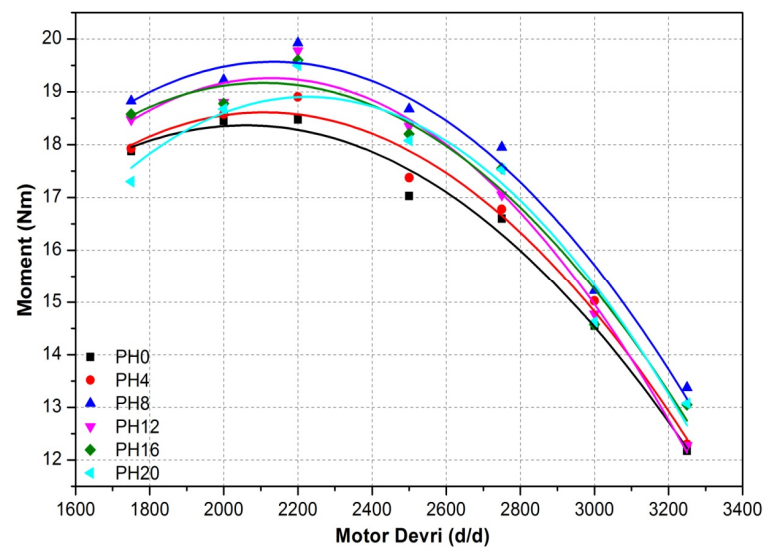

Şekil 4. Motor momentinin motorun devir sayısı ile değişimi (tam yük) (Change of engine torque with engine speed-full load)

Motor gücünün düşük devirlerde yanma veriminin kötü olmasından dolayı düşük çıktığı düşünülmektedir. Orta devirlerde yanmanın iyileşmesinden dolayı bütün test yakıtları için motor gücü artış göstermektedir. Ancak orta devirlerden sonraki devirlerde motor gücü düşmektedir. Bu durum artan devirle birlikte yanma için ayrılan sürenin azalması ve sürtünmelerdeki artışla izah edilebilir [18]. Biyodizelin n-heptan karışım yakıtlarına göre yüksek viskozite ve yoğunluğu; yakıtın silindir içerisindeki nüfuzunu, atomizasyonu etkiler ve yakıt/hava karışımının kötüleşmesine sebep olur. nheptan ilave edilen yakıtların viskozite ve yoğunluğu PH0 yakıtından düşüktür. n-heptan ilave edilen yakıtların motor gücü ve momentinin yüksek olması atomizasyonunun iyi ve yanma verimliliğinin artmasının sonucu olduğu düşünülebilir. Bunun nedeni n-heptanın düşük sicaklık ve düşük basınçta soğuk alev bölgesinde daha iyi yanma özelliği 
sergilemesidir [15]. Xue ve ark. [19] yapmış oldukları çalışmada biyodizelin viskozite ve yoğunluğundaki azalmanın motor gücü ve torkunu olumlu yönde etkilediğini belirtmişlerdir. n-heptan karışım yüzdesinin artmasıyla motor gücü ve momentteki artış da düşmektedir. n-heptan karışımının belirli bir sınırda tutulması motor gücü açısından önemlidir. Ayrıca n-heptan karışım yüzdesinin sınırı yakıt özelliklerini etkilediği için yakıtın kullanılabilirliği açısından da çok önemlidir.

Şekil 5'de tam yükte silindir gaz basınç grafiği görülmektedir. Maksimum silindir gaz basincı PH8 yakıtında 64.51 bar ve ÜÖN'dan yaklaşık $6.48{ }^{\circ} \mathrm{KA}$ sonra meydana gelmiştir. Bir dizel motorunun en iyi yakıt ekonomisi, maksimum yanma sonu basıncinın ÜÖN'dan 6-10 ${ }^{\circ} \mathrm{KA}$ sonraya rastlaması durumunda elde edilebilmektedir [20]. n-heptan karışımıyla moleküller arası bağın kırılmasıyla viskozitenin azaldığı ve setan sayısının arttığı düşünüldüğünde maksimum silindir gaz basıncındaki artış anlaşılabilir [21]. Zhang ve Boehman [22] yapmış oldukları çalışmada n-heptanın dizel motorlarda kullanımında maksimum silindir gaz basıncı ve sıcaklığında ciddi artışlar olduğunu belirtmişlerdir. Tam yükte tüm yakıtlar için maksimum silindir gaz basınçları hemen hemen aynı krank açısında ( $\left.{ }^{\mathrm{K}} \mathrm{KA}\right)$ oluşmuştur. Maksimum silindir gaz basıncın artması ile net iş alanı arttığından elde edilen güçte buna orantılı olarak artmaktadır [23]. Fakat maksimum silindir gaz basıncındaki artış belli bir yakıt yüzdesinden sonra negatif yönde gerçekleşmekte olduğu görülmektedir. Bunun sonucunda n-heptanın biyodizel içerisine belli bir karışım yüzdesi sınırı olmalıdır. Basınç grafikleri incelendiğinde silindir gaz basınçlarındaki artışın güç grafiği ile uyumlu olduğu görülmektedir.

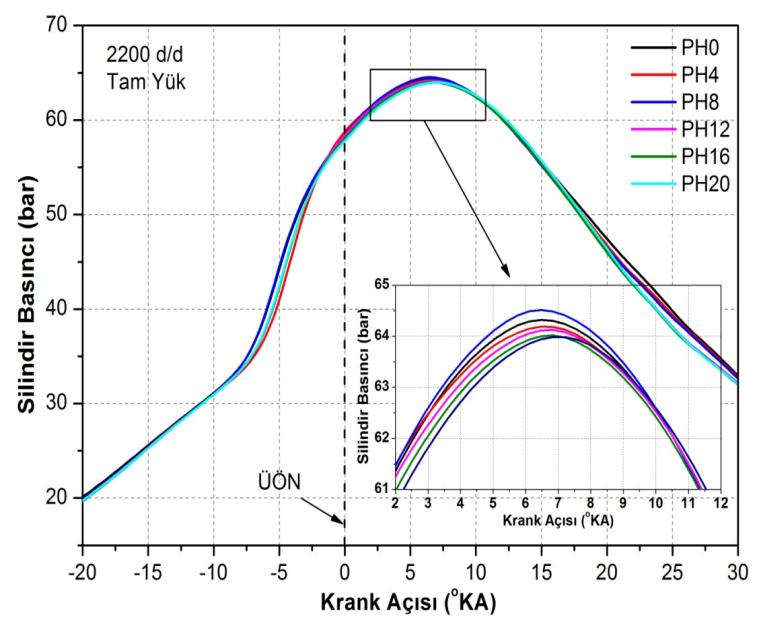

Şekil 5. Silindir içi gaz basıncının krank açısı ile değişimi (Variation in-cylinder gas pressure with crank angle)

Şekil 6'da tam yükte elde edilmiş örnek bir 1S1 yayılımı grafiği görülmektedir. Dizel motorlarda enjeksiyon başlangıcı ve yanma başlangıcı arasında geçen süre tutuşma gecikmesi olarak adlandırılmaktadır (I. Bölge). Tutuşma gecikmesi; fiziksel gecikme ve kimyasal gecikme süresi olarak tanımlanır [24,25]. Püskürtülen yakıt yanma odası boyunca küçük damlacıklara ayrılarak buharlaşır. Yakıtın yanmaya hazır hale gelmesi için geçen süreye fiziksel gecikme denir. Fiziksel gecikme süresi yakıt damlacıklarının buharlaşması ve atomizasyonu ile alakalı olduğu için; püskürtme basıncına, enjektör türüne, yanma odası tasarımına, yakıt özelliklerine bağlıdır. Fiziksel gecikme süresinden sonra meydana gelen kimyasal gecikme silindir içerisindeki sıcaklığa ve yakıt özelliklerine büyük ölçüde bağlıdır [26].

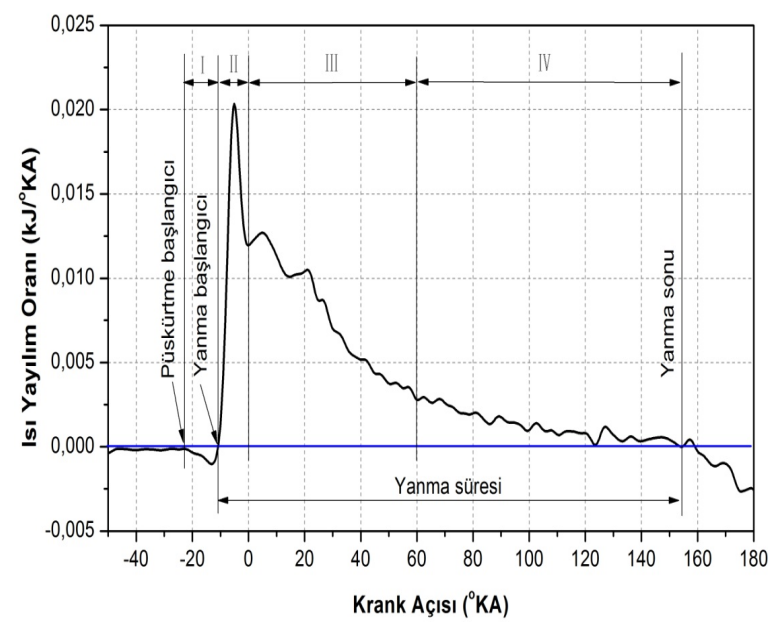

Şekil 6. Yanma fazları ve yanma süresinin belirlenmesi (Combustion phases and determination of combustion duration)

Tutuşma gecikmesi süresinde yakıt buharlaşırken ortamdan 1Sı çektiği için 1sı yayılımı negatif olur daha sonra 1S1 yayılımın pozitife döndüğü yer yanma başlangıcı olarak tanımlanır. Tutuşma gecikmesi bittikten sonra kontrolsüz yanma safhası başlar (II. Bölge). Kontrolsüz yanma safhasında 1sı yayılımının yüksek olmasının en önemli nedeni tutuşma gecikmesi süresinde püskürtülen yakıt miktarının artmasıdır [27]. Dizel yanmasının, ana yanmayı oluşturan üçüncü fazı difüzyon kontrollü yanma safhasıdır (III. Bölge). Bu safhada 1Sı yayılımı eğrisinde bir miktar artış olmaktadır. Bu artışın değeri püskürtülen yakıt miktarına ve yakıtın oksitlenme miktarına bağlıdır [11]. Yakıt buharının buharlaşma ve hava ile karışma hızı, yanma hızını belirlemektedir. Yanma sürecinde maksimum sıcaklığa ulaşıldıktan sonra art yanma fazı başlamakta olup (IV. Bölge), silindire yakıt püskürtme işlemi bitmiştir. Art yanmada, yanma hızı difüzyon hızı ve karışım oluşum hızı ile belirlenmektedir. Daha önce püskürtülen ve yanma firsatı bulamayan yakıt, oksijen buldukça yanmakta ve bu safhayı meydana getirmektedir. Is1 yayılımının bu yanma fazında sıfıra düştüğü nokta yanma sonu olarak tanımlanmaktadır. Yanmanın egzoz zamanına geçilmeden önce tamamlanması gerekmektedir [28,29]. Isı yayılımının negatiften pozitife döndüğü nokta (yanma başlangıcı) ile pozitiften negatife döndüğü nokta (yanma sonu) arası yanma süresini belirlemektedir. 
Şekil 7'de tam yükte test yakıtları ile elde edilen 1sı yayılım eğrileri görülmektedir. Grafik incelendiğinde kontrolsüz yanma safhasinda maksimum is1 yayılımının PH4 yakitında $0.0230 \mathrm{~kJ} /{ }^{\circ} \mathrm{KA}$ olarak meydana geldiği görülmektedir. Daha sonra sırasıyla PH8, PH16, PH20, PH12 ve PH0 yakitlarında 0.0220 - $0.0215-0.0213-0.0205-0.0203 \mathrm{~kJ} /{ }^{\circ} \mathrm{KA}$ olmuştur. Maksimum 1Sı yayılımı krank açısına göre birbirine çok yakın noktalarda meydana gelmiştir. Şekil 8'de tam yükte yakıt türüne göre yanma süresinin değişimi görülmektedir. Yanma süresi; yanmanın başladığı nokta ile kümülatif 1sı yayılımının \% 90 olduğu krank açısı asındaki süreye göre hesaplanmaktadır [27]. Tutuşma gecikmesinin fazla olması sonucu yanma başlangıcı daha geç ${ }^{\circ} \mathrm{KA}$ konumunda gerçekleşir. Bunun sonucunda 1Sı yayılım oranındaki çok hızlı bir şekilde artar ve yanma süresi kısalır. [17]. Minimum yanma süresi PH0 yakıtında meydana gelmiştir. Dizel ile kıyaslandığında biyodizel \%10-12 ağırlığında oksijen içerir. Yakıt içerisindeki n-heptan karışım oranının artması ile yakıt içerisindeki oksijen içeriğinin azalması ve setan sayısının artması nedeniyle yanma süresinin arttı̆̆ görülmüştür [30,31].

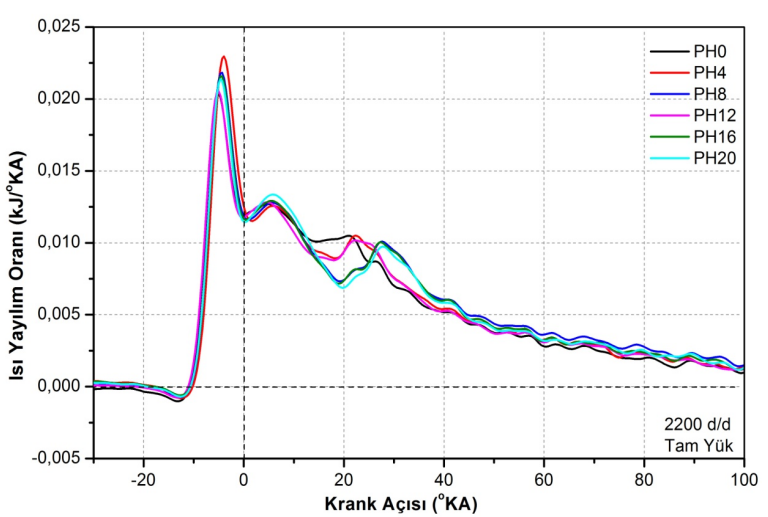

Şekil 7. Isı yayılımı oranının krank açısı ile değişimi (Variation heat release of rate with crank angle)

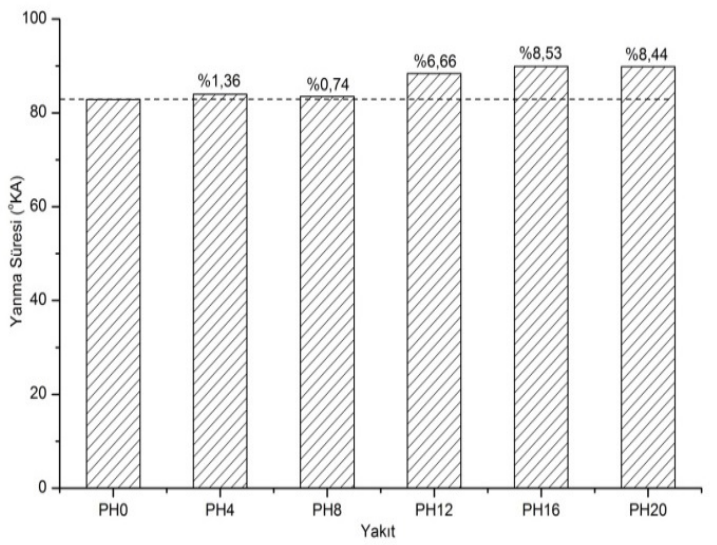

Şekil 8. Yakıt türüne göre yanma süresinin değişimi (tam yük) (Change of fuel type combustion time-full load)

Şekil 9'da basınç artış oranı grafiği görülmektedir. Yakıt içerisindeki n-heptan oranının artışıyla birlikte maksimum basınç artış oranı artmaktadır. Tüm test yakıtlarında maksimum basınç artış oranı hemen hemen ayn $1{ }^{\circ} \mathrm{KA}$ meydana gelmektedir. Bu n-heptan karışım oranının artmasıyla parlama noktasının azalmasından kaynaklandığı düşünülebilir [31]. Tutuşma gecikmesi ve yanma süresinin uzayarak genişleme zamanına kayması maksimum basınç artış oranı üzerinde etkiye sahiptir [17].

Şekil 10'da tutuşma gecikmesi grafiği görülmektedir. En kısa tutuşma gecikmesi PH8 yakıtında $12.88{ }^{\circ} \mathrm{KA}$ olmuştur. Tutuşma gecikmesi PH0, PH4, PH12, PH16 ve PH20 yakıtlarında sırasıyla $13.14-13.81-13.38$ - 13.27 ve $13.34{ }^{\circ} \mathrm{KA}$ olmuştur. Setan sayısı düşük yakıt uçuculuğu ve buharlaşması için daha yüksek gizli 1sıya sahiptir. $\mathrm{Bu}$ nedenle yakıt püskürtme anında ve uzun tutuşma gecikmesi süresinde daha fazla miktarda 1sı emmesine neden olur [32].

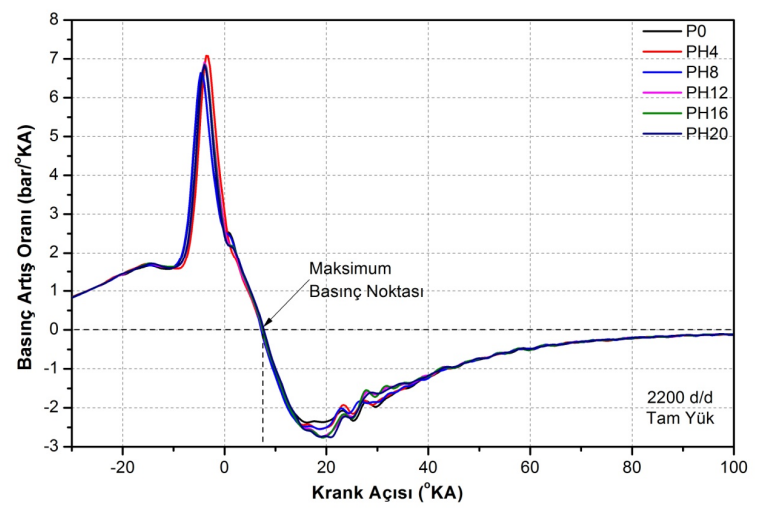

Şekil 9. Basınç artış oranının krank açısı ile değişimi (Variation pressure rise of rate with crank angle)

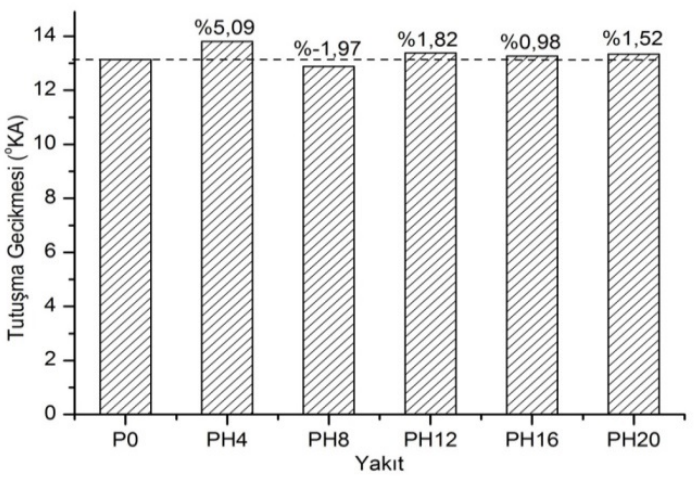

Şekil 10. Yakıt türüne göre tutuşma gecikmesi süresinin değişimi (tam yük) (Change of fuel type ignition delay period-full load)

Şekil 11'de maksimum egzoz gazı sıcaklığı görülmektedir. Maksimum egzoz gazı sıcaklığı PH8 yakitında $565{ }^{\circ} \mathrm{C}$ olurken $\mathrm{PH0}$ yakitında $563{ }^{\circ} \mathrm{C}$ olmuştur. Maksimum egzoz gazı sıcaklığı PH4, PH12, PH16 ve PH20 yakitlarında sirasiyla 550, 554, 560 ve $558{ }^{\circ} \mathrm{C}$ olmuştur. Egzoz gazı sicaklığının artması tutuşma gecikmesi ile açıklanabilir. Uzun tutuşma gecikmesi süresi yanma işlemini genişleme strokuna kaydıracağından silindir içi sıcaklık ve basıncı 
düşürecektir. Buda egzoz gazı sıcaklığının düşmesine neden olduğu düşünülebilir [33].

Şekil 12'de ortalama efektif basınç grafiği incelendiğinde en yüksek ortalama efektif basınç değeri PH8 yakıtında oluşmaktadır. Maksimum ortalama efektif basınç 7.12 bar olurken diğer test yakitlarında sirasiyla PH0'da 6.90, PH4'de 6.92, PH12'de 7.05, PH16'da 7.04 ve PH20'de 6.97 bar olmuştur.

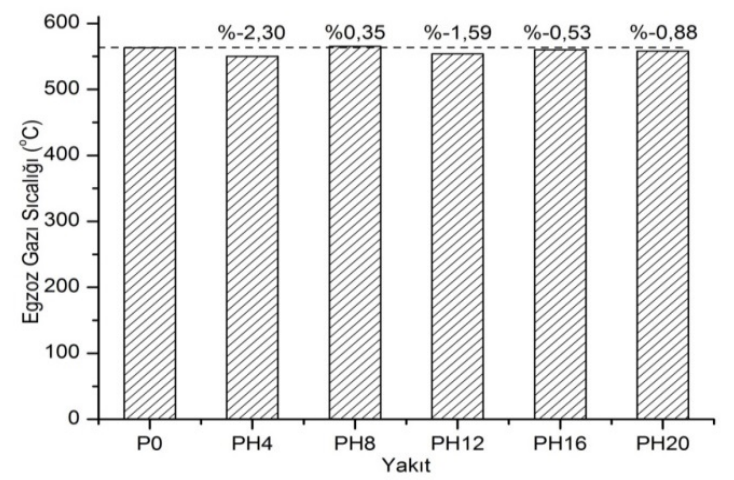

Şekil 11. Yakıt türüne göre egzoz gazı sıcaklığı değişimi (tam yük) (Change of fuel type exhaust gas temperature-fuel load)

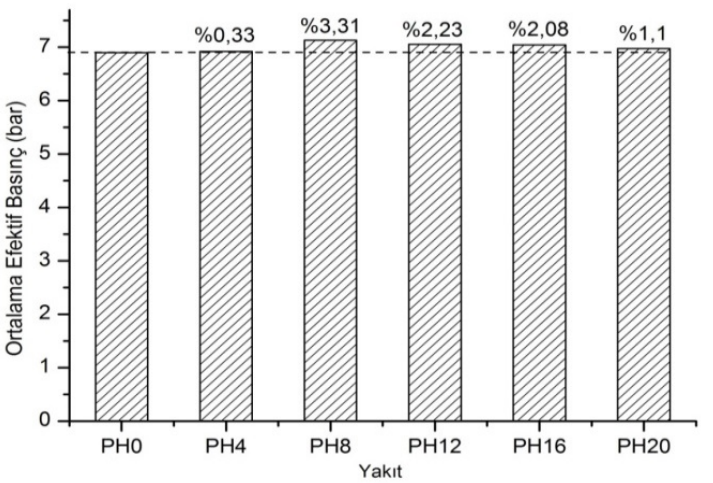

Şekil 12. Yakıt türüne göre ortalama efektif basınç değişimi (tam yük) (Change of fuel type mean effective pressure-full load)

\section{SONUÇLAR (CONCLUSIONS)}

Maksimum moment ve güç PH8 yakıtında elde edilmiştir. n-heptan ilave edilen yakıtların moment ve güçleri PH0 yakıtına göre daha yüksek olmuştur.

Maksimum silindir gaz basıncı PH8 yakıtında 64.51 bar ve ÜÖN'dan yaklaşık $6.48{ }^{\circ} \mathrm{KA}$ sonra meydana gelmiştir. n-heptan karışımıyla moleküller arası bağın kırılmasıyla viskozitenin azalmasına bağlı maksimum silindir gaz basıncındaki artış olmuştur. Maksimum 1sı yayılımı kontrolsüz yanma safhasında PH4 yakıtında meydana gelmiştir. Daha sonra sırasıyla PH8, PH16, PH20, PH12 ve PH0 yakıtlarında olmuştur. Maksimum 1S1 yayılımı ve maksimum silindir gaz basınçları krank açısına göre birbirine çok yakın noktalarda meydana gelmiştir. n-heptan karışım yüzdesinin artmasıyla birlikte maksimum 151 yayılımı azalmaktadır.

En kısa tutuşma gecikmesi PH8 yakıtında olmuştur. Tutuşma gecikmesi süresinin artmasıyla egzoz gazı sıcaklığı düşmektedir.

Yapılan deneyler sonucunda en iyi sonucu veren nheptan yüzdesi $\% 8$ olmuştur. n-heptan karışım yüzdesinin artmasıyla motor gücü ve momentteki artış da düşmektedir. n-heptan karıșımının belirli bir sınırda tutulması motor performansı açısından önemlidir. Ayrıca n-heptan karışım yüzdesinin sınırı yakıt özelliklerini etkilediği için yakıtın kullanılabilirliği açısından da çok önemlidir.

\section{TEŞEKKÜR (ACKNOWLEDMENT)}

$\mathrm{Bu}$ deneysel çalışma Gazi Üniversitesi-Bilimsel Araştırma Birimi Tarafindan 07/2013-05 No'lu proje ile desteklenmiştir.

\section{KAYNAKLAR (REFERENCES)}

1. Keskin, A. Ocakoğlu, K. Reşitoğlu, İ.A. Gürü, M., "Influence of Titanium Based Fuel Additive on Diesel Engine Performance and Emission", Journal of the Faculty of Engineering and Architecture of Gazi University, Cilt 28, No 3, 671-676, 2013.

2. Alptekin, E. Çanakc1, M., "Determination of the Density and the Viscosities of Biodiesel- Diesel Fuel Blends", Renewable Energy, Cilt 33, 2623 2630, 2008.

3. Lopez, D.E. Goodwin J.G. David A. Bruce, D.A. Lotero, E., "Transesterification of Triacetin with Methanol on Solid Acid and Base Catalysts Applied Catlysis”, A: General, Cilt 295, 97-105, 2005.

4. Çelikten, İ. Gürü, M. "Improvement of Performance and Emission Criterias of Petrodiesel and Rapeseed Oil Biodiesel with Manganese Based Additive", Journal of the Faculty of Engineering and Architecture of Gazi University, Cilt 26, No 3, 643-648, 2011.

5. Resmi Gazete, 27 Eylül 2011 tarih 28067 sayı.

6. Thoo, W.J. Kevric, A. Ng, H.K. Gan, S. Shayler, P., "Characterisation of Ignition Delay of Period for a Compression Ignition Engine Operating on Blended Mixtures of Diesel and Gasoline", Applied Thermal Engineering, Cilt 66, 55-64, 2014.

7. Park, S.H. Kim, H.J. Suh, H.K. Lee, C.S., "Experimental and Numerical Analysis of SprayAtomization Characteristics of Biodiesel Fuel in Various Fuel and Ambient Temperatures Condition", International Journal of Heat and Fluid Flow, Cilt 30, 960-970, 2009. 
8. Keskin, A. Gürü, M. Altıparmak, D., "Influance of Metallic Based Fuel Additives on Peformance and Exhaust Emissions of Diesel Engine", Energy Conversion and Management, Cilt 52, 60-65, 2011.

9. Shahabuddin, M. Liaquat, A.M. Masjuki, H.H. Mofijur, M., "Ignition Delay, Combustion and Emission Characteristics of Diesel Engine Fueled with Biodiesel", Renewable and Sustainable Energy Reviews, Cilt 21, 623-632, 2013.

10. Vallinayagam, R. Vedharaj, S. Yang, W.M. Lee, P.S. Chua, K.J.E. Chou, S.K., "Combustion Performance and Emission Characteristics Study of Pine Oil in a Diesel Engine", Energy, Cilt 57, 344-351, 2013.

11. Türkcan, A. Çanakçı, M. Özsezen, A.N. Sayın, C., "Investigation of Combustion Characteristics of a Diesel Engine", Journal of the Faculty of Engineering and Architecture of Gazi University, Cilt 21, No 1, 1-10, 2009.

12. Gogoi, T.K. Baruah, D.C., "The Use of Koroch Seed Oil Methyl Ester Blends as Fuel in a Diesel Engine”, Aplied Energy, Cilt 88, 2713-2725, 2011.

13. Apdulvahitoğlu, A., Performance and Exhaust Emission Characteristics of A CI Engine Fueled With Synthesized Fuel Blends, Phd Thesis, Cukurova University Instute Of Natural and Applied Sciences, Adana, 2009.

14. Donkerbroek, A.J., Combustion in an Optical Diesel Engine Studies by Light-Based Diagnostics, Nijmegen, Nedherlands, 2010.

15. Kolaitis, D.I. Founti, M.A., "On the Assumption of Using n-heptane as a Surrogate Fuel for the Description of the Cool Flame Oxidation of Diesel Oil", Proceedings Of The Combustion Instute, Cilt 32, 3197-3205, 2009.

16. Merck KGaA, “104379 n- heptane”, 2014.

17. Can, Ö., Bir DI Dizel Motorda Etanol Ön Karışımlı Kısmı-HCCI Uygulamasının Yanma ve Emisyon Üzerine Etkilerinin İncelenmesi, Doktora Tezi, Gazi Üniversitesi, Fen Bilimleri Enstitüsü, Ankara, 2012.

18. Hazar H. Temizer İ. Gür, F., "Effect of Additive Meterials on Engine Performance and Parts in a Diesel Engine", 6th International Advanced Tecnologies Symposium, Frrat Üni., Elazıg, 7783, 16-18 Mayis 2011.

19. Xue, J. Grift, T.E. Hansen, A.C. "Effect of Biodiesel on Engine Performances and Emissions", Renewable and Sustainable Energy Reviews, Cilt 15, 1098-116, 2011.

20. Çetinkaya, S., Termodinamik, Nobel Akademik Yayıncılık, Ankara, Türkiye, 1999.

21. Rao, G.L.N. Prasad, B.D. Sampath, S. Rajagopal, K., "Combustion Analysis of Diesel Engine Fueled with Jatropha Oil Methyl Ester Diesel Blends", International Journal of Green Energy, Cilt 4, 645-658, 2007.
22. Zhang, Y. Boehman, A.L., "Autoignition of Binary Fuel Blends of n-heptane and $C_{7}$ Esters in a Motored Engine", Combustion and Flame, Cilt 159, 1619-1630, 2012.

23. Polat, S. Solmaz, H. Yücesu, H.S. Uyumaz, A., "Bir Dizel Motorun Bilgisayar Yardımı ile Termodinamik ve Performans Analizi”, GU J Sci Part C, Cilt 1, No 3, 139-151, 2013.

24. Challen, B. Baranescu, R., Diesel Engine Referance Book, Second Edition, India, 1984.

25. Heywood, J.B., Internal Combustion Engine Fundamentals, McGraw Hill Book Comp., New York, A.B.D., 1988.

26. Finesso, R. Spessa, E., "Ignition Delay Prediction of Multiple in Diesel Engine", Fuel, Cilt 119, 170-190, 2014.

27. Sakthivel, G. Nagarajan, G. Ilangkumaran, M. Gaigwad, A.B., "Comparative Analysis of Performance, Emission and Combustion Parameters of Diesel Engine Fuelled with Ethyl Ester of Fish Oil and its Diesel Blends", Fuel, Cilt 132, 116-124,2014.

28. Safgönül, B. Ergeneman, M. Arslan, E. Soruşbay, C., İçten Yanmalı Motorlar, Birsen Yayınevi, İstanbul, Türkiye, 1995.

29. Ergen, G., Ön Isıtma Uygulanarak Kullanılan Biyodizel Yakıtının Motor Performans ve Emisyonlarına Etkisinin İncelenmesi, Yüksek Lisans Tezi, Sakarya Üniversitesi, Fen Bilimleri Enstitüsü, Sakarya, 2006.

30. Gürü, M. Koca, A. Can, Ö. Çınar, C. Şahin, F., "Biodiesel Production From Waste Chicken Fat Based Sources and Evaluation with Mg Based Additive in a Diesel Engine", Renewable Energy, Cilt 35, 637-643, 2010.

31. Dhar, A. Agarwad, A.K., "Performance, Emissions and Combustion Characteristics of Karanja Biodiesel in a Transportation Engine", Fuel, Cilt 119, 70-80, 2014.

32. Devan, P.K. Mahalakshmi, N.V. "A Study of the Performance, Emission and Combustion Characteristics of a Compression Ignition Engine Using Methyl Ester of Paradise Oil-Eucalyptus Oil Blends", Applied Energy, Cilt 86, 675-680, 2009.

33. Yoon, S.H. Lee, C.S., "Experimental Investigation on the Combustion and Exhaust Emission Characteristics of Biogas-Biodiesel Dual-Fuel Combustion in a CI Engine", Fuel Processing Technology, Cilt 92, 992-1000, 2012.

34. Srivastava, P.K. Verma, M., "Methyl Ester of Karanja Oil as an Alternative Renewable Source Energy", Fuel, Cilt 87,1673-1677, 2008.

35. Gürü, M. Artukoğlu, B.D. Keskin, A. Koca, A., "Biodiesel Production From Waste Animal Fat and Improvement od its Characteristics by Synthesized Nichel and Magnesium Additive" Energy Conversion and Management, Cilt 50, 498-502, 2009. 
36. Çaynak, S. Gürü, M. Biçer, A. Keskin, A. İçingür, Y., " Biodiesel Production From Pomace Oil and Improvement of its Properties with Synthetic Manganese Additive", Fuel, Cilt 88, 534-538, 2009.

37. Nabi, N. Rahman, M. Akhter, S., "Biodiesel From Cotton Seed Oil and its Effect on Engine
Performance and Exhaust Emissions", Applied Thermal Engineering, Cilt 29, 2265-2270, 2009. 38. Predojevic, Z.J., "The Production of Biodiesel From Waste Frying Oils: a Comparison of Different Purification Steps" Fuel, Cilt 87, 35223528, 2008. 
